\title{
Automobilske navlake od prirodne kože - svojstva i problematika šivanja
}

\section{dr. sc. Beti Rogina-Car, dr. sc. Stana Kovačević, prof. Sveučilište u Zagrebu Tekstilno-tehnološki fakultet}

E-mail: beti.rogina-car@ttf.hr

Stručni rad

UDK: $675.14 .017: 629.3 .04$

\section{Sažetak}

U radu je dan pregled materijala i specifičnosti izrade automobilskih navlaka u prometalima. Naglasak je na prirodnoj koži koja predstavlja jedan od najluksuznijih materijala za izradu automobilskih navlaka. Obrađena su njezina svojstva, prednosti i nedostatci u odnosu prema tekstilnim materijalima. Jedan od najizazovnijih zadataka u izradi automobilskih navlaka jest kvaliteta odgovarajućeg šava. Posebna pozornost posvećena je krojenju i šivanju prirodne kože namijenjene automobilskim navlakama. Prirodna koža je specifičan prirodni materijal koji daje dozu luksuza automobilskim sjedalima $i$ interijeru automobila. Njezina dugotrajnost, cijena i manja tržišna ponuda dovodi do manje primjene za automobilske navlake u odnosu prema tekstilnim materijalima, ali je zato iznimno poželjna. Prema dosadašnjim istraživanjima krojenje i šivanje kožnih automobilskih navlaka zahtijeva veću pozornost pri odabiru odgovarajuće kože, šivaćeg stroja, konca, igle i tipa šivanog šava, koji će dati zadovoljavajuća svojstva automobilskoj navlaci u svim njezinim segmentima. Ovaj rad pridonosi stručnim saznanjima i specifičnostima vezanim za prirodnu kožu, njezinu namjenu za automobilska sjedala te odgovarajuću kvalitetu šivanog šava.

\section{Ključne riječi}

prirodna koža, automobilska navlaka, svojstva prirodne kože, šivani šav.

\section{Uvod}

Materijali koji se upotrebljavaju za automobilske navlake u prometalima izrađeni su od različitih materijala raznim tehnološkim procesima. Prirodna koža jedan je od najskupljih, ali i najpoželjnijih materijala koji se upotrebljava za automobilske navlake i interijer automobila. Svojim iznimno lijepim i luksuznim izgledom privlači kupca te pridonosi

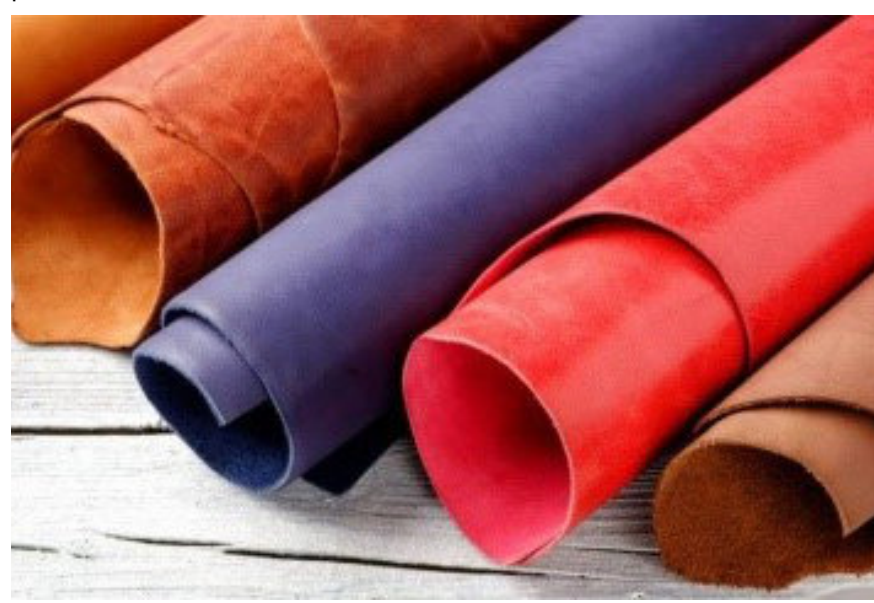

Slika 1. Prirodna koža [1]

Za izradu kožnih automobilskih navlaka upotrebljavaju se iznimno čvrste prirodne životinjske kože: bikova, kravlja, teleća, konjska, svinjska, kozja i ovčja koža. Koža je vrlo izdržljiv i otporan materijal, ali istodobno elastičan i dišljiv. Pozitivna svojstva prirodne kože jesu: visoka čvrstoća, elastičnost, otpornost na abraziju, dobra propusnost zraka, mekoća i glatkoća. Zbog visoke cijene i iznimno dobrih svojstava prava se koža uglavnom ugrađuje u skuplje automobile kod kojih kupac želi poseban i originalan interijer [2].

\section{Svojstva prirodne kože}

Prerada životinjske kože pripada najstarijim ljudskim djelatnostima. To potvrđuju bilješke na babilonskim glinenim pločicama iz 1250. godine prije Krista. Čovjek je kožu upotrebljavao od svojeg postanka kako bi se zaštitio od vanjskih utjecaja, napada ljudi i životinja, Slika 2. [3, 4].

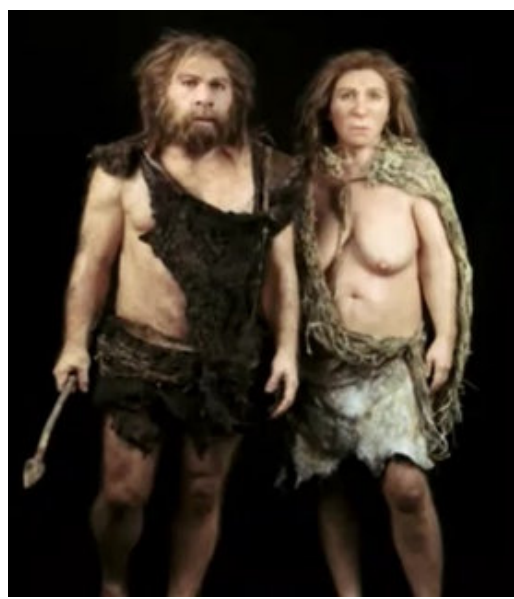

Slika 2. Neandertalac, Hušnjakovo brdo kod Krapine [3]

S vremenom se koža osušila i postala tvrda. Izložena vlazi počela je gnjiljeti te se raspadati. Postupkom štavljenja koža dobiva potrebnu trajnost. Prvi postupci štavljenja bili su dimljenje i obrada kože mastima i moždinama ubijenih životinja. Danas se postupak štavljenja provodi u rotirajućim bačvama u trajanju od 10 do 12 sati. Štavila mogu biti anorganske soli: kromove, aluminijeve, cirkonijeve; biljna štavila: ekstrakti nekih tropskih i suptropskih biljaka. Primjena štavila omogućava umrežavanje kolagenskih vlakna čime koža zadržava mekoću i elastičnost te postaje čvršća, otpornija na truljenje, manje propusna za vodu itd. Koža se prema podrijetlu dijeli na prirodnu i umjetnu kožu; prema prirodnom 
izvoru dijeli se na goveđu (teleću), ovčju, kozju, svinjsku, konjsku, aligatorovu, zmijsku kožu itd.; prema svrsi postoji koža za obuću, odjeću, galanteriju, automobilsku i zrakoplovnu industriju te za industriju namještaja itd. [4]

Na izgled i kvalitetu prirodne kože utječu životni uvjeti u kojima je životinja uzgojena. Tragove na koži ostavljaju ubodi insekata, rane, ožiljci, vene, bore, oznaka brenda itd., Slika 3.[5]

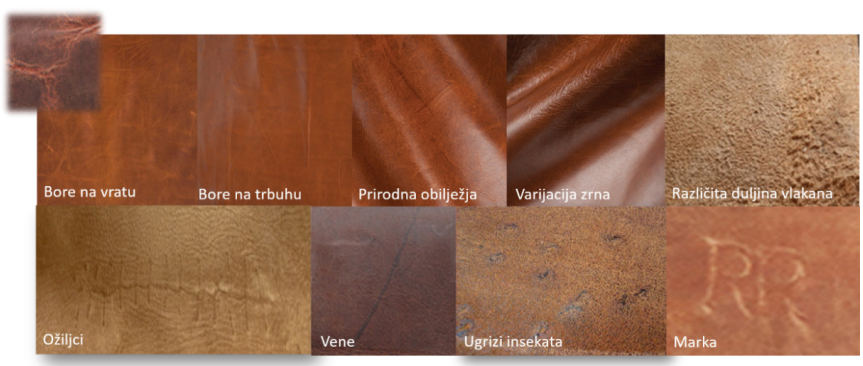

Slika 3. Tragovi - prirodna obilježja na koži životinja [5]
Svojstva prirodne kože koja su važna za primjenu u automobilskoj industriji kod automobilskih navlaka jesu: otpornost na abraziju, otpornost na plijesan, otpornost na dugotrajna i ciklička naprezanja, elastičnost, čvrstoća, stabilnost oblika, mekoća i ugoda pri dodiru s tijelom, svojstvo dišljivosti, rubovi iskrojenih dijelova se ne osipaju, lako održavanje [1]. U Tablici 1. prikazana je usporedba svojstava nekih materijala koji se primjenjuju za automobilske navlake [6].

Tablica 1. Usporedba materijala koji se primjenjuju za automobilske navlake [6]

\begin{tabular}{|c|c|c|c|c|c|}
\hline & $\begin{array}{c}\text { Otpornost na } \\
\text { propuštanje vode }\end{array}$ & Žilavost & Mekoća & Dišljivost & $\begin{array}{c}\text { Otpornost na } \\
\text { plijesan }\end{array}$ \\
\hline Prirodna koža & ++ & ++ & ++ & + & $\mathrm{Da}$ \\
\hline Polycotton Drill & + & ++ & ++ & ++ & $\mathrm{Da}$ \\
\hline Spancer Mesh & + & + & + & +++ & $\mathrm{Da}$ \\
\hline Velur & + & + & +++ & + & $\mathrm{Da}$ \\
\hline Neoprene (Neosupreme) & ++ & + & ++ & + & $\mathrm{Da}$ \\
\hline Neoprene (Genuine) & +++ & ++ & ++ & ++ & $\mathrm{Da}$ \\
\hline Umjetna koža & ++ & ++ & + & + & $\mathrm{Da}$ \\
\hline Antilop & + & + & +++ & + & $\mathrm{Da}$ \\
\hline
\end{tabular}

+ dobar; ++ vrlo dobar; +++ izvrstan

Iz Tablice 1. vidljivo je da prirodna koža u usporedbi s ostalim materijalima ima vrlo dobra svojstva. Ako se usporedi s antilopom, može se vidjeti velika razlika u svojstvima. Razlog u takvoj razlici svojstava jest u tome što se antilop proizvodi od donjeg dijela životinjske kože koja je mekša, ali osjetljivija na druga svojstva.

\section{Automobilske navlake od prirodne kože}

Primjer dobre prakse jest tvrtka Wollsdorf Leather koja se specijalizirala za proizvodnju kože namijenjene automobilskoj i zrakoplovnoj industriji te industriji namještaja. Predvodnik je u štavljenju prirodne kože bez kroma. Upotrebljavaju prvoklasne goveđe kože podrijetlom uglavnom sa srednjoeuropskog prostora [7].

Ergonomski dobro oblikovana sjedala osigurat će optimalno držanje tijela, ugodno sjedenje, pružit će osjećaj sigurnosti i prostranosti tijekom duže vožnje. Izbor materijala, preciznost krojenja i kvalitativno spajanje dijelova automobilske navlake šivanjem imaju za cilj trajnost automobilske navlake barem onoliko koliko je prosječni životni ciklus automobila. Automobilska navlaka mora imati dimenzijsku stabilnosti, postojanosti boje na Sunčevu svjetlost, otpornost na abraziju i stabilnost šava. Jedno od iznimno važnih svojstava automobilskih navlaka jest kvalitativno spajanje njezinih dijelova, koji su često izrađeni od različitih materijala s različitim svojstvima, sirovinama, debljinama, tvrdoćama i sl. Prilagodba automobilske navlake zbog sve složenijih ergonomski prilagođenih sjedala zahtijeva ozbiljniji konstrukcijski pristup koji rezultira sve većim brojem krojnih dijelova koje treba spojiti. Povećava se broj šavova te se daje sve veća važnost kvaliteti šava. Danas jedna automobilska navlaka u prosjeku ima 15 krojnih dijelova za šivanje s duljinom šava oko $25 \mathrm{~m}$, dok po jednom automobilu u prosjeku ima 120 krojnih dijelova ukupne duljine šava oko $175 \mathrm{~m}$. Različitost materijala koji se upotrebljavaju za automobilske navlake (koža, skaj, tkanina, pletivo, netkani tekstil) ne omogućuje termičko ili bilo koje drugo spajanje, osim spajanja šivanim šavom. Razlika u debljinama i komponentama tekstilnih laminata dodatno otežava spajanje dijelova automobilskih navlaka. Pojava novih, mekših i podatnijih materijala s manjim debljinama (čupavljenje tkanine sa specijalnim kemijskim nanosima, kombinacija tkanina i netkanog tekstila s posebnim kemijskim i mehaničkim obradama te razne prirodne i umjetne kože $s$ dodatnim kemijskim obradama) ide u prilog kvalitetnijem spajanju šivanim šavom dijelova automobilskih navlaka [1]

Nedostatci, odnosno problemi koji postoje u primjeni prirodne kože odnose se na veličinu kože i životni vijek životinje, prirodna obilježja koja je životinja za života dobila na koži, Slika 3. Prirodna koža različite je veličine i nepravilnog oblika. Prije krojenja provodi se kontrola kvalitete kože te obilježavanje pogrešaka, Slika 4.

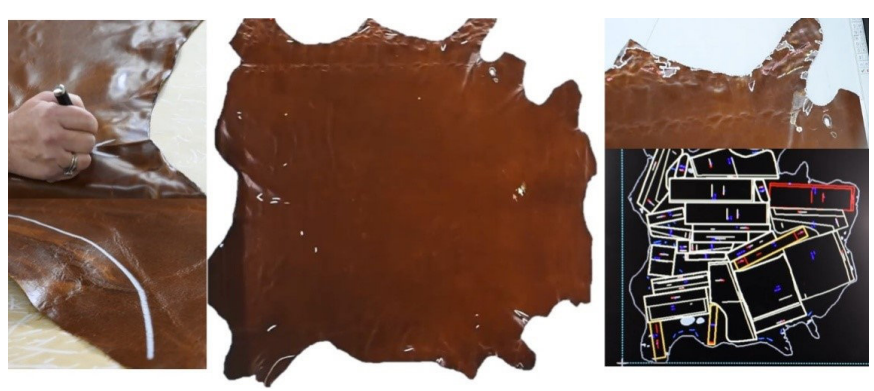

Slika 4. Obilježavanje pogrešaka na koži i prikaz krojne slike [8]

Nakon obilježavanja pogrešaka na koži slaže se krojna slika. Kod krojenja je potrebna iznimna preciznost, Slika 5 . Ako se previdi oštećenje na koži, primjerice, od uboda insekta to će poslije znatno skratiti vijek trajanja automobilske navlake [8]. 


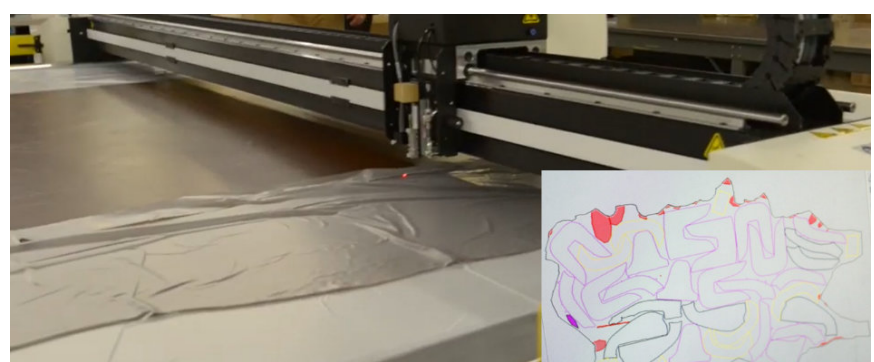

Slika 5. Proces krojenja kože (Gerber cutter)[9]

Jedan od nedostataka je i mijenjanje površine kože po kvaliteti, boji i izgledu pa je vrlo teško proizvesti automobilsku navlaku jednoličnog obojenja i kvalitete. Promatrajući s drugog aspekta to može biti prednost u unikatnosti koja se cijeni na tržištu prometala. Sukcesivnim razvrstavanjem kože mogu se dobiti najprikladniji tonovi kože koji će dati poseban dezen automobilske navlake, ali to zahtijeva poskupljenje proizvodnje, veća znanja o materijalima, dezenima, bojama koja su aktualna na tržištu.

\section{Proces spajanja automobilskih navlaka šivanim šavom}

Pri izradi kožnih automobilskih navlaka većina karakterističnih tehnoloških operacija šivanja izvodi se na univerzalnom šivaćem stroju koji šiva dvostrukim zrnčanim ubodom tipa 301 [10]. Vrlo je važno odabrati pravi tip šivaćeg šava prema standardu ISO 4916. Prema normi šivani je šav niz šivaćih uboda ili niz tipova šivaćih uboda upotrijebljenih na jednom sloju materijala ili za spajanje više slojeva materijala [11]. U Tablici 2. prikazani su najčešće upotrebljavani tipovi šivaćih šavova kod šivanja kožnih automobilskih navlaka.

Tablica 2. Prikaz tipova šivaćih šavova [10 - 13]

\begin{tabular}{|c|c|c|}
\hline Slika šava & $\begin{array}{c}\text { ISO 4915 } \\
\text { Tip šivaćeg uboda }\end{array}$ & $\begin{array}{c}\text { ISO 4916 } \\
\text { Tip šivaćeg šava }\end{array}$ \\
\hline & & $1.01 .01 / 301$ \\
\hline & & \\
\hline
\end{tabular}

Igleni konci prema standardu označavaju se brojevima 1, 2, 3 itd., dok se donji konci označavaju malim slovima a, b, c itd. [14]. Tipovi šivanih šavova normirani su prema ISO 4916 [11]. Vrsta šivanog šava sastoji se od pet znamenki. Prva znamenka - skupina šivanog šava (1 - 8), druga i treća znamenka - raspored slojeva materijala za šivanje (01 - 99), četvrta i peta znamenka - položaj uboda ili probijanja igle (01 - 99) [14]. Na Slici 6. prikazana je kožna automobilska navlaka i interijer luksuznog automobila marke BMW obložen prirodnom kožom. Istaknuti su karakteristični tipovi šavova [15 - 18]
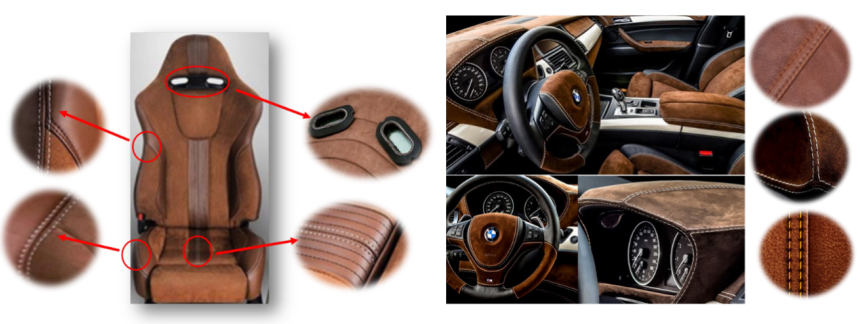

Slika 6. Kožno automobilsko sjedalo i interijer luksuznog automobila marke BMW obložen prirodnom kožom [15 - 18]

Šivanje automobilskih navlaka zahtijeva robusnije šivaće strojeve prilagođene šivanju debljih i višeslojnih materijala. Stroj za šivanje treba moći šivati materijale različitih sirovina i debljina bez oštećenja igle, konca materijala. Primjer šivaćih strojeva za šivanje kožnih automobilskih navlaka tvrtke Dürkopp Adler, Slika 7. Njihova optimalna brzina šivanja jest oko $2800 \mathrm{~min}^{-1}$. Mogu biti izrađeni s produženom glavom i slobodnom rukom kako bi se olakšalo rukovanje materijalom veće površine tijekom šivanja.

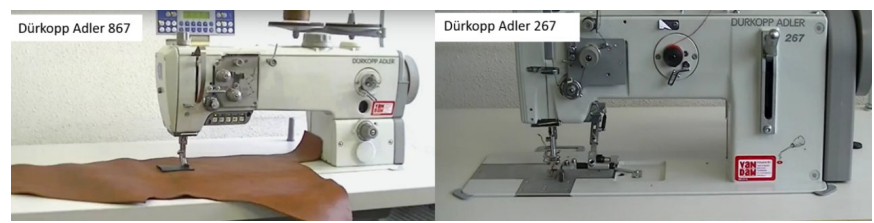

Slika 7. Šivaći strojevi namijenjeni šivanju kožnih automobilskih navlaka tvrtke Dürkopp Adler [19]

Kod šivanja kožnih automobilskih sjedala najčešće se upotrebljava dvostruka pritisna nožica. Sastoji se od vanjske pritisne nožice koja služi pridržavanju materijala i unutarnje pritisne nožice koja pomaže u transportu materijala, Slika 8.

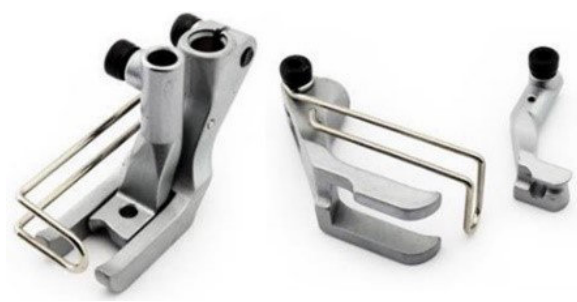

Slika 8. Dvostruka pritisna nožica s izdvojenim dijelovima tvrtke Dürkopp Adler [20]

Svi tehnološki parametri šivanja koji utječu na kvalitetu šava trebaju se međusobno uskladiti, počevši od materijala koji se šiva, konca, brzine šivanja, posmika materijala, opremljenosti stroja i vrste igala. Materijal, igla i konac za šivanje čine jedinstvenu skupinu koja izravno utječe na kvalitetu šava. Svaki segment gornjega konca prođe 25 do 60 puta kroz ušicu igle dok se ne dovede $u$ kontakt $s$ donjim koncem i ušije $u$ materijal. Posebna pozornost pridaje se šivaćoj igli, odnosno vrhu igle, površinskoj obradi i materijalu koji je na površini igle. Igla treba imati i određenu tvrdoću te dobru toplinsku vodljivost kako bi se što manje oštetio materijal na mjestu uboda i pravilno oblikovao šav. Za šivanje kožnih automobilskih navlaka po pravilu se upotrebljavaju igle $s$ vrhovima namijenjene sječenju kože. $\mathrm{Na}$ taj način smanjuje se trenje i olakšava prolazak konca kroz kožu. Poprečni presjek vrha igle nije okrugao, već je najčešće elipsastog ili trokutastog oblika, Slika 9. [1, 21].

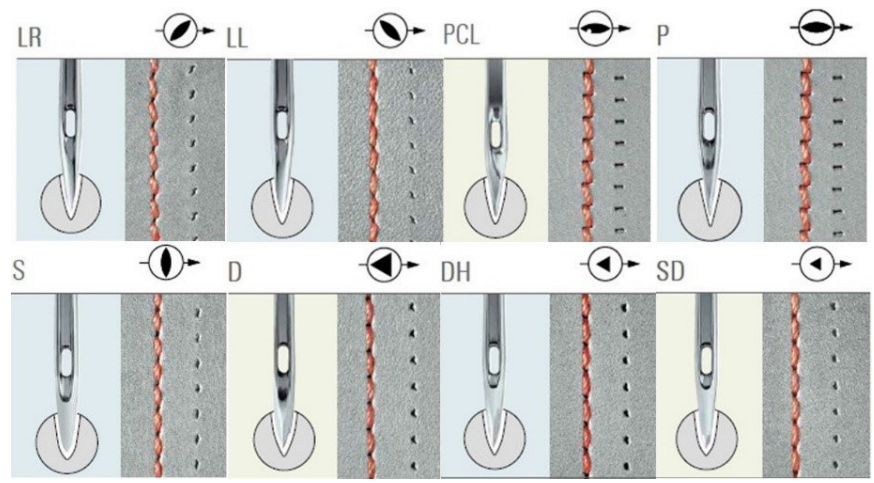

Slika 9. Vrste vrhova strojnih šivaćih igala za šivanje kože [21]

Ovisno o vrsti i debljini materijala te potrebnoj čvrstoći šava odabire se duljina i vrsta uboda, finoća konca i vrsta igle. Svojstva konca za šivanje automobilskih navlaka najčešće su slijedeća finoća: 50 - 105 tex, čvrstoća: 40 - $80 \mathrm{cN} /$ tex, prekidno istezanje: 20 - $30 \%$, modul elastičnosti: $0.5-4 \mathrm{cN} / \mathrm{tex}$, sirovinski sastav: poliester, poliamid [22].

\section{Zaključak}

Tehnološki proces šivanja kožnih automobilskih navlaka jest zahtjevan i složen proces. Potrebno je dobro uskladiti sve parametre u tehnološkom procesu šivanja kako bi se postigla zadovoljavajuća kvaliteta šava. Pogreške kod šivanja kože nisu dopuštene, bilo da je riječ o zaostalim oštećenjima na koži ili oštećenjima prilikom šivanja. Kožne automobilske 
navlake i kožni interijer automobila luksuz su koji zahtijeva iznimnu kontrolu prije krojenja, šivanja i postavljanja u automobil. Prirodna koža sadržava mnoga zaostala obilježja koja nije moguće otkloniti pa imaju važnu ulogu u procjeni kvalitete i iskoristivosti kože. Mogu predstavljati greške koje treba izbjeći u krojenju, ali neka obilježja koja zadovoljavaju potrebnim svojstvima mogu dati izvornost i neponovljivost automobilskih navlaka, u konačnici cjelokupnom interijeru automobila daje unikatni luksuzni izgled koji se iznimno cijeni u automobilskoj industriji.

\section{Literatura}

1. https://www.olx.ua/obyavlenie/naturalnaya-kozha-kreyzi-horscrazyhorse-krs-IDB2HDd.html, Pristupljeno: 2019-09-22

2. Kovačević, S.; Ujević, D. 2013. Seams in car seat coverings: properties and performance, Joining Textiles. Chapter No.: 16, I. Jones, G.K. Stylios (ed.), Oxford, Cambridge, UK: Woodhead Publishing Ltd, 478-506, DOI: 10.1533/9780857093967.4.478, ISBN: 078-1-84569-627-6.

3. https://edutorij.e-skole.hr/share/proxy/alfresconoauth/edutorij/ api/proxy-guest/ b52a40b8 3b f7-4d5c-bb15-65a258050885/biologija8/m01/j03/index.html, Pristupljeno:2019-10-05

4. Mužic, M.; Hitrec, P. 2004. Preradba životinjske kože. Hrvatska enciklopedija. Sv. 6: Kn - Mak; Zagreb: Leksikografski zavod Miroslav Krleža, str. 216 - 216; ISBN 953-6036-36-3.

5. https://www.leathersatchel.com/guides/care-guide/natural-leathermarkings/, Pristupljeno: 2019-09-30

6. https://www.coverking.com/water-resistant-neoprene-seat-cover.html, Pristupljeno: 2019-09-30

7. https://www.wollsdorf.com/w/hr/our_leather/production/, Pristupljeno: 2019-09-26

8. https://www.crlaine.com/media/wysiwyg/cms/ understanding-naturalleather/leather-bottom.jpg, Pristupljeno: 2019-09-29

9. https://www.boxmark.com/cutting_143.htm, Pristupljeno: 2019-09-26

10. ISO 4915:1991 Textiles - Stitch types - Classification and terminology

11. ISO 4916:1991 Textiles -- Seam types -- Classifi cation and terminology

12. https://www.slideshare.net/umailsushant/stitch-type-threadconsumption, Pristupljeno: 2019-09-20

13. https://www.academia.edu/10367446/type_of_stitches, Pristupljeno: 2019-09-26

14. Rogale D. i sur. 2011. Procesi proizvodnje odjeće. Zagreb, Tekstilnotehnološki fakultet.

15. https://www.pinterest.com/pin/292452569524253710/?nic=1, Pristupljeno: 2019-09-30

16. https://www.pinterest.com/pin/292452569524253735/, Pristupljeno: 2019-09-30

17. http://www.thehogring.com/2013/08/09/intersecting-2-french-seams/, Pristupljeno: 2019-09-30

18. https://www.crowworks.com/upholstery/flat-felled-seam-1/, Pristupljeno: 2019-09-30

19. https://www.youtube.com/watch?v=pjFsukk6mO4, Pristupljeno: 201909-28

20. https://www.images-na.ssl-imagesamazon.com/images/l/31fd\%2BIXu-YL.jpg, Pristupljeno: 2019-09-28

21. https://leatherworker.net/forum/uploads/monthly_2017_03/58cae0c13 4520_LeatherNeedlePointsG-B.jpg.3ec6a76cf559cdcb9941135ebb7 cdc97.jpg, Pristupljeno: 2019-09-30

22. Ujević, D. et al. 2002. Impact of Joined Place on the Fabric Intended for Manufacturing Car Seat Covers. 2nd AUTEX Conference, Bruges, Belgium, 1-3 July. 